\title{
Research on Technology of Supporting in Super-Large Section Cut in Working Face with Large Mining Height
}

\author{
Zhicheng Ren and Minghui Zuo \\ School of Energy and Mining, China University of Mining and Technology (Beijing), Beijing 100083, China \\ Correspondence should be addressed to Minghui Zuo; 263232856@qq.com
}

Received 8 May 2021; Accepted 17 August 2021; Published 14 October 2021

Academic Editor: Dezhong Kong

Copyright (C) 2021 Zhicheng Ren and Minghui Zuo. This is an open access article distributed under the Creative Commons Attribution License, which permits unrestricted use, distribution, and reproduction in any medium, provided the original work is properly cited.

\begin{abstract}
For the support problem of the super-large section cut in working face with large mining height, the 1105 cut pilot chamber of Zhaogu No. 2 Mine, the roof strata structure detection and the strata movement rule research were conducted. The results prove that concentrate fracture area, gradually sparse fracture area, and rare fracture area regularly distributed from the surface to the deep area of the roof of 1105 cut, and less fracture exists in the rock stratum of roof above $3.5 \mathrm{~m}$, and the stratum of roof within the range of 4-6 $\mathrm{m}$ is stable. Authors propose the long bolt and cable combined supporting technology and optimized the design plan applying theoretical calculation and computer numerical simulation. The scheme has been applied in the field of the 1105 superlarge section cut in Zhaogu No. 2 Mine. The monitoring results show that the scheme can effectively control surrounding rock of roadway, and the support with long bolt has good effectiveness.
\end{abstract}

\section{Introduction}

As the coal mine high yield and high efficient working face advance and further improve the degree of mechanization, especially the use of large mining heights, working face equipment is becoming larger and larger, and the open cut span of working face is also increasing, which increases the difficulty of support and maintenance. The support problem of the super-large cross-section open cut has become an important problem in the field of coal mine safety [1-11]. In terms of technology, the research on the prevention and control measures of rock burst has also been constantly improved, and the pressure relief method has made rapid progress. A variety of methods have been successfully used to prevent rock burst at home and abroad $[10,12,13]$. In this study, the large-diameter boreholes in the coal roadway pressure relief mechanism and reasonable parameters further research will be conducted. At the same time, it analyzes the layout direction, diameter, hole spacing, hole depth parameters, and their reasonable combinations of largediameter boreholes, so that to provide extremely important theoretical support for the practical application and popularization of large-diameter borehole pressure relief technology and has great practical application value.

\section{Project Overview}

The 1105 working face is the first large mining height working face of the Zhaogu No. 2 Mine, with an elevation of -636 to $-618 \mathrm{~m}$, which is a typical deep buried layout. The No. 2 coal seam is mainly mined at the 1,105 large mining height working face. The average thickness of the No. 2 coal seam is $6.32 \mathrm{~m}$. The false roof is mainly mudstone and carbonaceous mudstone less than $0.5 \mathrm{~m}$, which are only scattered in this area and generally fall with the mining. The thickness of the direct roof is generally $1.0-6.5 \mathrm{~m}$, which is dominated by mudstone roof and accounts for $70 \%$ of the coal bearing area. The distribution area of sandstone is about $20 \%$ of the coal bearing area and sandy mudstone accounts for $15 \%$ of the coal bearing area. The old roof thickness is $0.94-19.85 \mathrm{~m}$, and the average thickness is $7.46 \mathrm{~m}$ siltstone. The mechanical strength of the roof sandstone is medium, and the mudstone siltstone is medium-low, which belongs to the roof with medium-low management degree. The floor of 
the second coal seam is dominated by mudstone and sandy mudstone, with a thickness of 9.1-17.27 $\mathrm{m}$, with an average of $12.84 \mathrm{~m}$. The comprehensive coal and rock layer of the working face is shown in Figure 1.

The cutout of the 1105 working surface is a rectangular section with a design length of $180 \mathrm{~m}$, a height of $4.62 \mathrm{~m}$, a normal section width of $9.2 \mathrm{~m}$, and a nose and tail section width of $10.2 \mathrm{~m}$. During tunneling construction, the small section guide adit shall be tunneled first, the width of which is $4.8 \mathrm{~m}$, and the support shall be expanded to the normal section before installation.

\section{Supporting Mechanism of 1105 Super-Large Section Open Cut}

3.1. Fine Detection of Roof Rock Structure. Thickness of roof strata and the intensity have an important effect on roof stability, but due to the complexity of coal-forming environment and geological changes, different positions of roof rock strata thickness and strength can produce a very big change; in order to get the roof strata structure features of 1105 cut, thirteen roof detection boreholes are uniformly arranged in the guide tunnel of the off-cut, and the rock structure peeping instrument is used to detect the roof layering, layer thickness, rock cracks, and lithology to provide a basis for the design of the later off-cut support. The fine detection results of the roof rock formations show that the lithology within $10 \mathrm{~m}$ above the roof of the 1105 notch is relatively simple, the lower part is sandy mudstone with low strength and low cohesion, and the upper part is fine-grained sandstone; along the axial direction of the notch, the roof sandy mudstone layers at both ends are thinner than the middle part of the cut, and the ends of the fine-grained sandstone layers are slightly thicker than the middle. There are many cracks in the shallow part of the roof. The closer the roof is to the surface, the more fractured the surrounding rock is. From the surface of the roof to the deep part, there are different characteristics, such as dense fracture zone, sparse fracture zone, and rare fracture zone. In most boreholes, the fractures above $3.5 \mathrm{~m}$ are not particularly obvious. Based on the above rock structure characteristics, the length of anchor rod should be increased after the brush cross-section, and the anchorage end should be extended above the fissure dense area to ensure the stability of the roof in the shallow fissure dense area.

3.2. Movement Law of Rock Stratum on the Roof of Guide Tunnel. After the excavation of the guide tunnel, the original design plan is adopted for the combined support of bolts and cables. The bolt specifications are $20 \mathrm{~mm} \times 2400 \mathrm{~mm}$ rebar resin bolts, the row spacing between the top bolts is $800 \mathrm{~mm} \times 800 \mathrm{~mm}$, and the anchor cable specification is $21.6 \mathrm{~mm} \times 8250 \mathrm{~mm}$ anchor cable, with a row spacing of $1,600 \mathrm{~mm} \times 1,600 \mathrm{~mm}$. After the excavation of the roadway, the stress of the surrounding rock on the roof is transferred and concentrated, and the layered roof is prone to separation failure after deformation. In order to grasp the separation failure area of the guide tunnel of the cutoff cut and judge the support effect, it is the bolt (cable) parameter that optimizes and determines the reasonable length of the anchor rod to obtain basic field data. Set up rock movement measurement stations on the roof of the guide tunnel and install $2.0 \mathrm{~m}$, $4.0 \mathrm{~m}, 6.0 \mathrm{~m}$, and $10.0 \mathrm{~m}$ at each measurement station. Observe base points at different depths. The monitoring curve of multibase displacement in the roof of the guide adit is shown in Figure 2.

The monitoring data show that the overall deformation of the roof increases rapidly after the opening of the openhole guide adit and gradually slows down. After $20 \mathrm{~d}$, the deformation of the roof is stable at about $150 \mathrm{~mm}$. The deformation of the roof mainly occurs within $4 \mathrm{~m}$ of the depth of the roof, accounting for about 80 of the overall deformation of the roof. Among them, the displacement of roof in the range of $2-4 \mathrm{~m}$ is about $50 \mathrm{~mm}$ because the common short bolt is not long enough to control the stability of rock stratum in this range. The displacement of the roof rock in the range of $4 \mathrm{~m}$ is close to coincide with the displacement of the rock in the range of $6 \mathrm{~m}$, and the displacement change trend is synchronized, indicating that the rock formation in the range of 4-6 $\mathrm{m}$ from the roof of the 1105 cutoff cut is relatively stable. The anchor end of the rod is extended to a range of 4-6 m, and the rock formation with a large displacement within the range of $4 \mathrm{~m}$ is suspended on the stable rock formation. Mechanically calculate stability of roof rock beam. After roadway excavation, the roof will bend and sink to a certain extent under the action of overlying strata load. With the increase of roadway section, the total subsidence of the roof will increase and the stability will be greatly reduced. The ultimate span formula of the simply supported beam of material mechanics was used to calculate the subsidence amount of the roadway roof, and a coordinate system is established as shown in Figure 3. The deflection at the left and right hinge supports of the boundary condition was equal to zero.

The bending moment equation of the beam is

$$
M(X)=\frac{q l}{2} x-\frac{1}{2} q x^{2}
$$

where $M$ is the bending moment of the beam, $q$ is the load of overlying strata, and $l$ is the rock beam span.

Substitute formula (1) into the approximate differential equation of the deflection curve of a straight beam:

$$
E I \omega^{\prime \prime}=-M(X),
$$

where $\omega \|$ is the second derivative of beam deflection, $E$ is the elastic modulus of roof rock mass, and $I$ is the moment of inertia of the roof rock beam.

The deflection curve equation of the roof beam is

$$
\omega=\frac{q x}{24 E I}\left(l^{3}-2 l x^{2}+x^{3}\right)
$$

Therefore, it is judged that the maximum deflection must be in the middle of the beam span, that is, at $x=1 / 2$. At this time, 


\begin{tabular}{|c|c|c|c|}
\hline legend & Thickness (m) & Lithology & Description \\
\hline \multirow{2}{*}{ 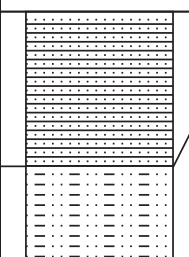 } & 10.37 & Siltstone & $\begin{array}{l}\text { Dark gray, Containing plant fossils, } \\
\text { Argillaceous cement }\end{array}$ \\
\hline & 6.5 & $\begin{array}{l}\text { Mudstone, } \\
\text { Sandy } \\
\text { mudstone }\end{array}$ & $\begin{array}{l}\text { Dark gray, Containing plant fossils and } \\
\text { a large number of siderite nodules }\end{array}$ \\
\hline & 6.32 & Coal & Black, Blocky, Metallic luster \\
\hline 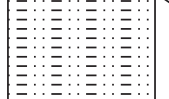 & 7.3 & $\begin{array}{c}\text { Sandy } \\
\text { mudstone }\end{array}$ & $\begin{array}{l}\text { Black gray, Contains plant } \\
\text { fossils and nodules }\end{array}$ \\
\hline E & 5.41 & Mudstone & $\begin{array}{l}\text { Dark gray, Containing plant fossils, } \\
\text { Silica cement }\end{array}$ \\
\hline
\end{tabular}

FIGURE 1: Comprehensive histogram of working face.

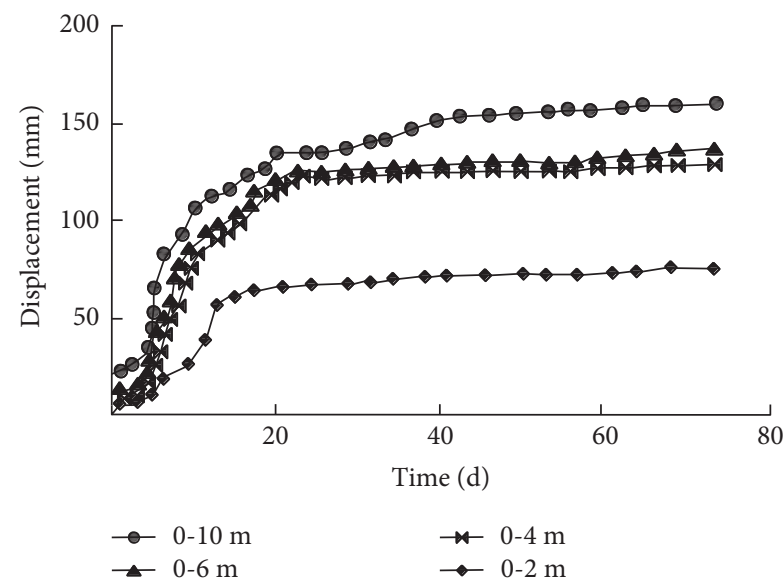

FIGURE 2: Multibase point displacement monitoring curve in the deep part of the guide tunnel roof.

$$
\omega_{\max }=\left.\omega\right|_{x=(l / 2)}=\frac{5 q l^{4}}{384 E I} .
$$

As the height of the roof rock beam remains unchanged, the moment of inertia of the roof rock beam is proportional to the span $l$ of the rock beam, namely,

$$
I=\frac{h^{3}}{12} l
$$

Substituting equation (5) into equation (4), that is, the maximum deflection of a rock beam with a roadway roof is

$$
\omega_{\max }=\frac{5 q l^{3}}{32 E h^{3}} \text {. }
$$

It can be seen from equation (6) that the maximum sinking deformation of the roadway roof is proportional to the third power of the roadway span $l$. For the 1105 cutoff, the previous monitoring data show that the deformation of the guide way roof is about $150 \mathrm{~mm}$, which is extended to normal. After the cross-section, the deformation of the top plate of the open cut will increase by 6-9 times, and the safety of the top

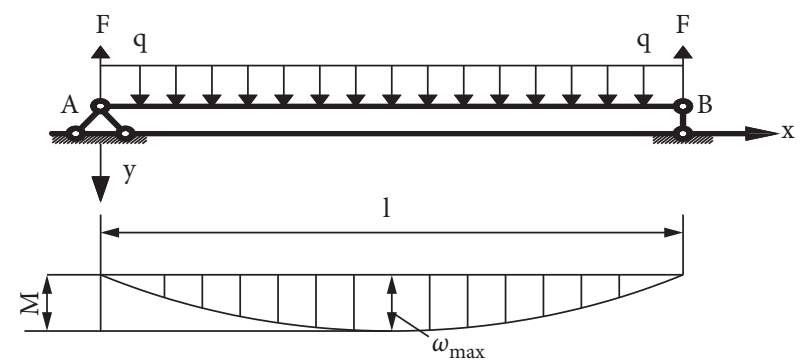

Figure 3: Mechanics model of simply supported beam of roadway roof.

plate cannot be guaranteed. Therefore, for the support of the super-large cross-section open cut, it is necessary to adopt measures such as erecting a column to reduce the span.

\section{Large Section Open Cut Support Plan}

4.1. Numerical Calculation of Long Bolt Support Scheme. Use FLAC numerical simulation software to calculate and compare the supporting effect of the long bolt support scheme and the original guide tunnel support scheme and further study the deformation displacement and stress distribution of the surrounding rock of the super-large section cutout. Establish a calculation model for the 1105 cut, the cut length is $180 \mathrm{~m}$, and the average thickness of the coal seam is $6.32 \mathrm{~m}$. The cutout section is rectangular, $9.20 \mathrm{~m}$ wide, and $4.72 \mathrm{~m}$ high. Both sides of the cut are solid coal. The calculation model selects the $x$-axis direction as the advancing direction along the working face and the $y$-axis direction as the vertical direction. In the $x$ axis direction, take $50 \mathrm{~m}$ to the left from the center line of the roadway and $50 \mathrm{~m}$ to the right. In the direction of the $y$-axis, take $36.5 \mathrm{~m}$ toward the top rock layer, add a uniform load to the upper boundary, and take $30.0 \mathrm{~m}$ toward the bottom rock layer. The constitutive relationship of the surrounding rock of the cut hole adopts the Mohr-Coulomb model. The mechanical parameters of coal and rock in the model are given in Table 1. Figure 4 is 
TABLE 1: Mechanical parameters of rock and coal in the calculation model.

\begin{tabular}{|c|c|c|c|c|c|c|}
\hline $\begin{array}{l}\text { Rock formation } \\
\text { name }\end{array}$ & $\begin{array}{c}\text { Density } \\
\left(\mathrm{kg} \mathrm{m}^{-3}\right)\end{array}$ & $\begin{array}{l}\text { Shear modulus } \\
(\mathrm{GPa})\end{array}$ & $\begin{array}{l}\text { Bulk modulus } \\
(\mathrm{GPa})\end{array}$ & $\begin{array}{c}\text { Cohesion } \\
(\mathrm{MPa})\end{array}$ & $\begin{array}{c}\text { Internal friction } \\
\text { angle }\left({ }^{\circ}\right)\end{array}$ & $\begin{array}{c}\text { Tensile strength } \\
(\mathrm{MPa})\end{array}$ \\
\hline Medium sandstone & 2420 & 9.477 & 10.264 & 12.18 & 40.33 & 3.536 \\
\hline Coarse sandstone & 2392 & 4.450 & 5.632 & 8.37 & 44.52 & 1.758 \\
\hline $2-1$ coal & 1450 & 2.130 & 6.389 & 4.2 & 32 & 1.050 \\
\hline Sandy mudstone & 2560 & 3.23 & 4.18 & 6.51 & 36 & 1.12 \\
\hline Mudstone & 2593 & 2.02 & 3.70 & 5.01 & 38 & 0.64 \\
\hline
\end{tabular}

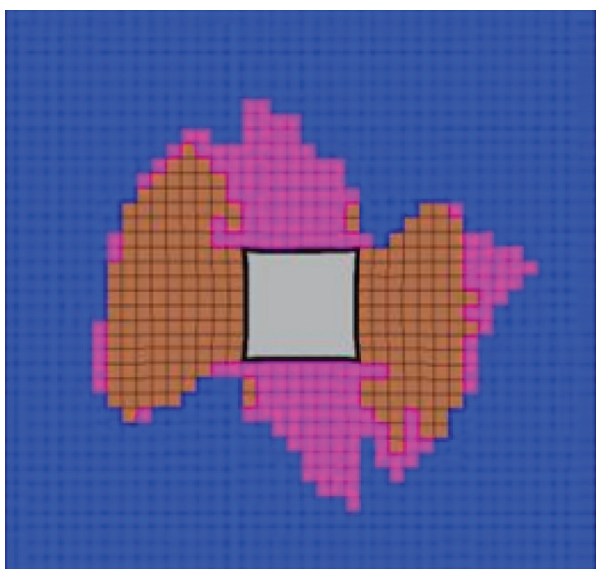

(a)

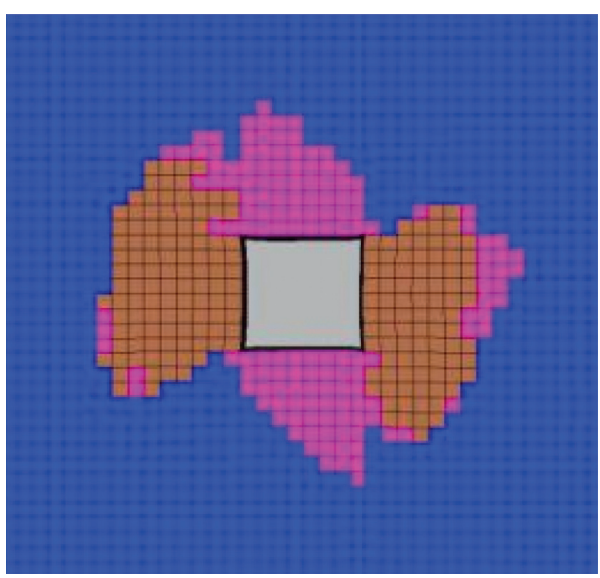

(c)

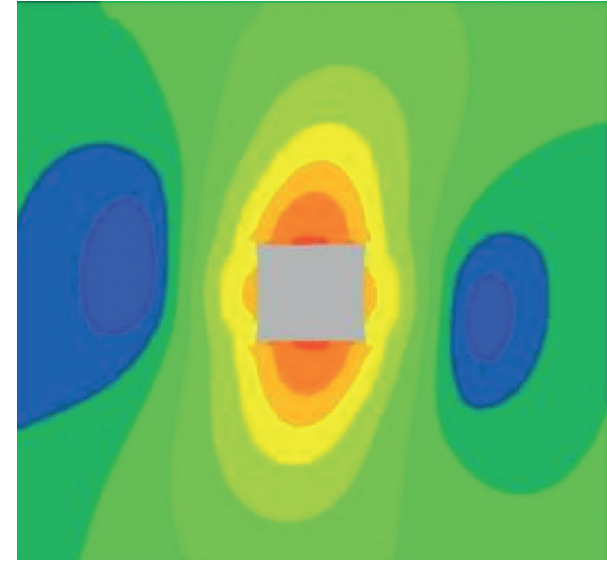

(b)

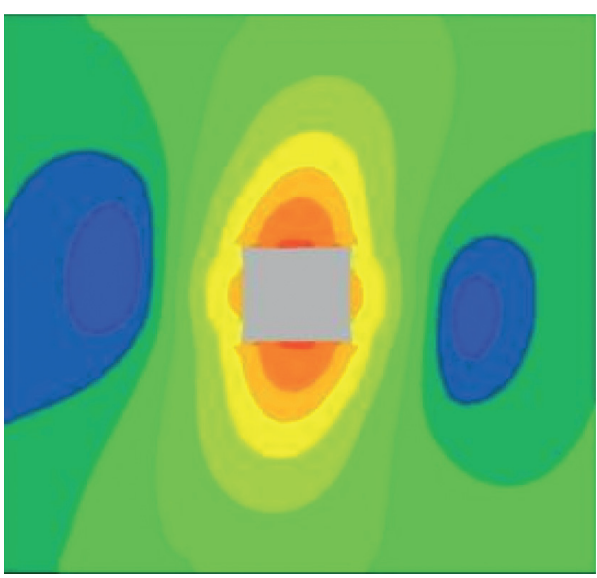

(d)

FigURE 4: Simulation of the plastic zone and stress distribution of different lengths of bolt support in the surrounding rock. (a) Ordinary bolt support scheme shaping area. (b) Stress distribution of ordinary bolt support scheme. (c) Long bolt support scheme shaping area. (d) Stress distribution of long bolt support scheme.

a simulation diagram of the shaping zone and stress distribution in the surrounding rock with different length bolts.

Figures 4(a) and 4(b) show that the maximum shaping area of the top plate in the middle of the original support plan is $5 \mathrm{~m}$, and the shaping range of the top plates near the two banks is gradually smaller than the middle. Due to the many cracks in the shallow part of the eye roof and the decrease in rock strength, the stress at $2 \mathrm{~m}$ from the roof reaches $10 \mathrm{MPa}$, and the stress at $3.2-6 \mathrm{~m}$ reaches $20 \mathrm{MPa}$. Figure 4(c) shows that the plastic failure of the top plate near the two sides is only $2 \mathrm{~m}$, and the plastic failure of the top plate in the middle of the cut reaches $4 \mathrm{~m}$, which is $1 \mathrm{~m}$ less than the plastic failure range when ordinary bolts are used (Figure 4(d)). It shows that as the distance between the top plates increases, the stress rises significantly. The stress rises to $10 \mathrm{MPa}$ in the range of $1-2 \mathrm{~m}$ and reaches $22.5 \mathrm{MPa}$ above $6.2 \mathrm{~m}$.

The above analysis shows that the surrounding rock shaping zone of the long bolt support scheme is smaller than the surrounding rock shaping zone of the original scheme. The ordinary bolts are all located in the plastic zone, while the long bolts can be anchored to the stable rock formation outside the plastic zone. 


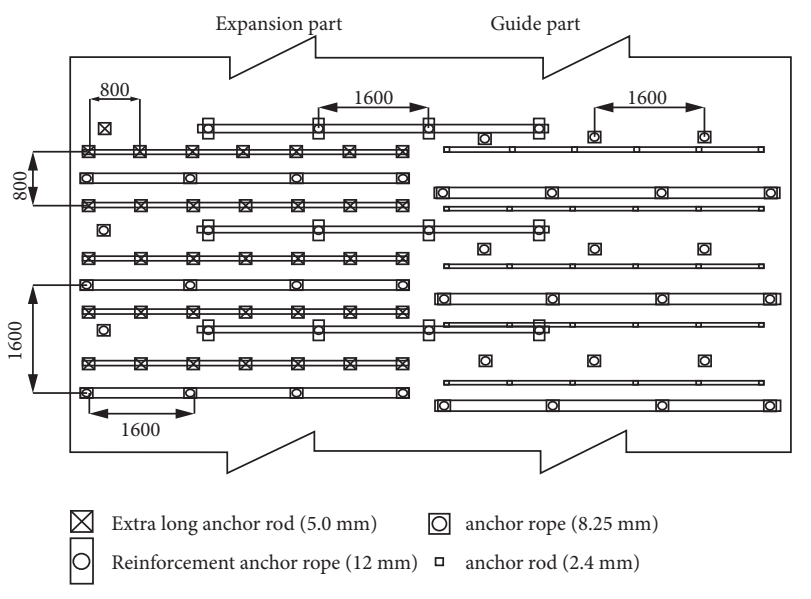

(a)

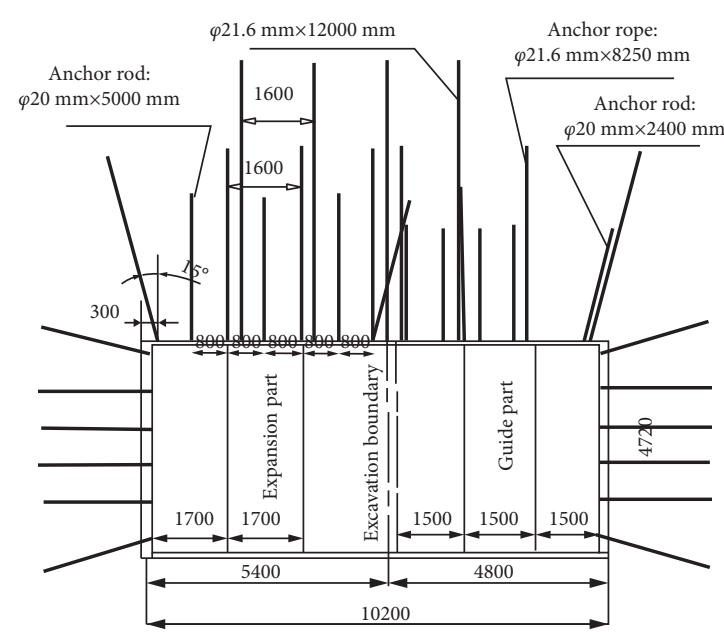

(b)

FIGURE 5: Layout of 1105 incisional eye support. (a) Layout plan of 1105 notch roof support. (b) Section view of top plate support layout of 1105 cut.

4.2. 1105 Super-Large Section Open Cut Support Plan. According to the results of fine detection of roof strata and numerical simulation of rock strata movement, the support scheme of 1105 super-large section cut holes with superlong bolt and anchor cable combined with rows of single pillar is determined.

(1) Roof support: the roof of the cutoff guide tunnel adopts $21.6 \mathrm{~mm}$ to construct 6 anchor rods, as shown in Figure 5(a). In addition, two rows of single pillars are erected to support the roof. The top plate after the cutout is enlarged, uses $20 \mathrm{~mm} \times 5000 \mathrm{~mm}$ superlong bolts with a row spacing of $800 \mathrm{~mm} \times 800 \mathrm{~mm}$, and each row at the top is constructed with 7 bolts; the anchor cables are in the middle of the cutout except for the anchor cables used on the roof of the guide tunnel. In addition, a $16 \mathrm{~mm} \times 12,000 \mathrm{~mm}$ reinforced anchor cable is installed, with a row spacing of $1,600 \mathrm{~mm} \times 1,600 \mathrm{~mm}$, and a pallet of $12 \mathrm{~mm} \times 400 \mathrm{~mm} \times 400 \mathrm{~mm}$,

$12 \mathrm{~mm} \times 200 \mathrm{~mm} \times 200 \mathrm{~mm} \times 200 \mathrm{~mm}$ steel plates, and $50 \mathrm{~mm} \times 200 \mathrm{~mm}$. Use wooden pads together. At the same time, erect two rows of single pillars to support the roof.

(2) Lane support: the bolt specifications are $20 \mathrm{~mm} \times 2400 \mathrm{~mm}$ rebar resin bolts, with a row spacing of $700 \mathrm{~mm} \times 800 \mathrm{~mm}$, and each row is constructed with 6 bolts. As shown in Figure 5(b), the pallet is made of $\mathrm{W}$-shaped steel belt and $10 \mathrm{~mm} \times 150 \mathrm{~mm}$. The $150 \mathrm{~mm}$ anchor rod tray is used in conjunction with the anchor rod and steel ladder to hit the stubble mesh. The metal mesh is welded with $5.6 \mathrm{~mm}$ steel bars, the mesh size is $900 \mathrm{~mm} \times 1700 \mathrm{~mm}$, the mesh is overlapped by $100 \mathrm{~mm}$, and each grid is tied with $14^{\#}$ lead wire.

(3) Supplementary materials: each top bolt uses one Z2360 resin anchoring agent and one CK2360 resin anchoring agent; each anchor bolt uses one Z2345

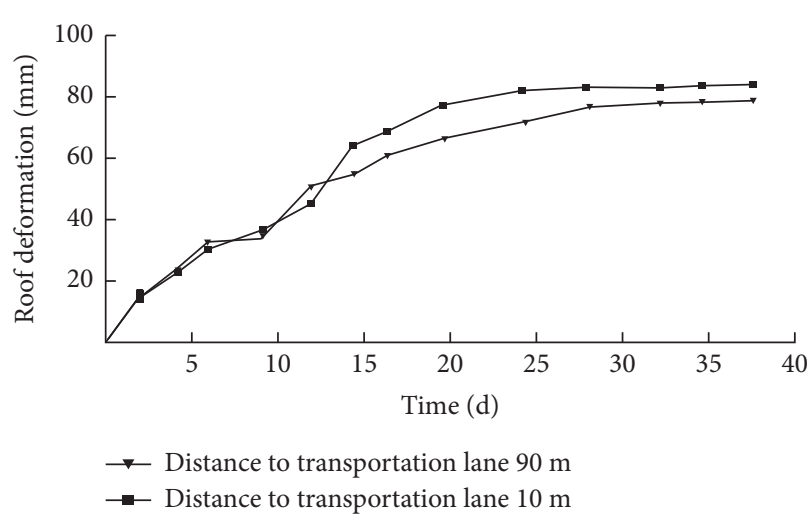

Figure 6: Deformation curve of the top plate of the open cut.

resin anchoring agent and one CK2345 resin anchoring agent; each anchor used two pieces of Z2360 resin anchoring agent and two pieces of CK2360 resin anchoring agent. The steel ladder is made of $14 \mathrm{~mm}$ round steel bars, the length of the steel ladder is $4160 \mathrm{~mm}$, and the width is $70 \mathrm{~mm}$.

\section{Support Effect Monitoring}

5.1. Displacement Monitoring of Open Cut Roof. In order to master the activity rule and supporting effect of the surrounding rock controlled by the long bolt and anchor cable supporting scheme and to provide data for the further improvement and optimization of supporting parameters in the future, the surface displacement of surrounding rock was observed during the construction process of extending the wall to the normal section. It can be seen from Figure 6 that after the secondary construction of the cutoff cut adopts the long anchor rod and the anchor cable support scheme, the overall roof deformation is small, and the displacement of the cutoff cut near the end of the mining roadway is greater than the top displacement in the middle of the cutoff cut and 


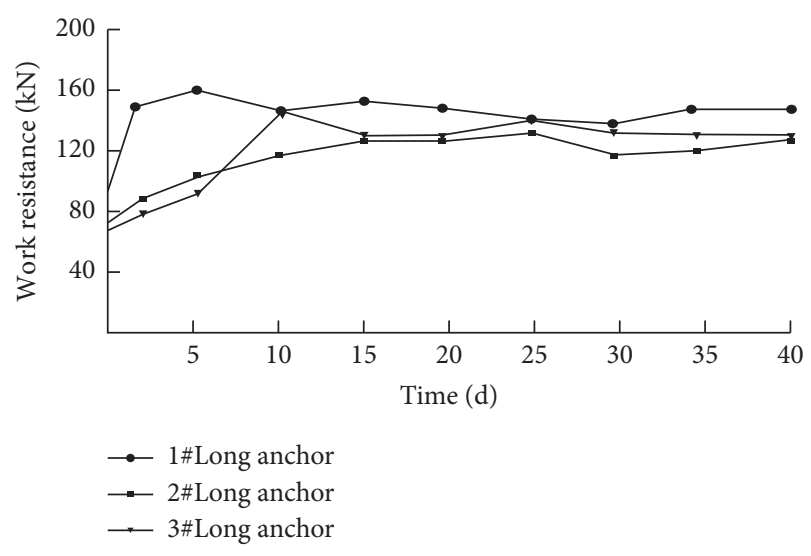

FIGURE 7: Working resistance curve of long anchor rod.

is closed to the end of the transportation roadway. The deformation becomes stable when the deformation reaches about $90 \mathrm{~mm}$, and the roof deformation in the middle of the cut (90 $\mathrm{m}$ away from the transportation lane) becomes stable when it reaches $75 \mathrm{~mm}$, which is less than the deformation of the guide tunnel roof of the cut (about $150 \mathrm{~mm}$ ).

5.2. Simulation Diagram of the Plastic Zone and Stress Distribution Generated in the Rock. During the construction process from the cut to the normal section, the support resistance of the superlong bolts used was monitored. In Figure 7 , the $1^{\#}, 2^{\#}$, and $3^{\#}$ long bolts are the supporting resistance curves of the long bolts at the center of the cut at $10 \mathrm{~m}, 90 \mathrm{~m}$, and $150 \mathrm{~m}$ away from the transportation roadway. The initial anchoring force of the extralong bolt is in the range of $50-100 \mathrm{kN}$, and it starts to receive the force stably when it reaches about $100-150 \mathrm{kN}$, and the overall supporting effect is good.

\section{Conclusion}

(1) According to the fine detection of the rock structure and the study on the law of rock strata movement, the shallow fractures in the roof of the super-large section 1105 of Zhaogu No. 2 mine densely developed, the fractures above $3.5 \mathrm{~m}$ are gradually sparse, and there is basically no separation in the ceiling within the range of $4-6 \mathrm{~m}$. In order to ensure the stability of the rock strata, long bolts should be used to anchor the shallow surrounding rocks to the stable rock strata.

(2) Superlong bolt combined with anchor cable support technology effectively controls the surrounding rock deformation of the super-large cross-section in Zhaogu No. 2 mine, solving the support problem of the super-large cross-section in Zhaogu No. 2 mine.

(3) The superlong bolt combined with anchor cable support technology is suitable for the roadway with great difficulty in surrounding rock control, such as the intersection of roadway with large broken overhanging roof area in the shallow section of large section. This technology has strong pertinence and wide application scope.

\section{Data Availability}

The data used to support the findings of this study are included within the article.

\section{Conflicts of Interest}

The authors declare that they have no conflicts of interest.

\section{References}

[1] Q. Liu and G. Xie, "Research and application of anchor mesh (cable) support for large cross-section cut holes in deep wells," China Coal, vol. 35, no. 7, 2009.

[2] H. Cui and Y. Hu, "Open-open cut support plan for large mining height working face," Coal Mine Safety, vol. 44, no. 2, 2013.

[3] H. Wang, Y. Yang, and J. Xi, "Research and application of anchor mesh (cable) support technology for long-span cut-off holes with composite roof," China Coal, vol. 2011, no. 2, pp. 59-62, 2011.

[4] J. Li, A. Li, and G. Wang, "Research on bolt support technology for large section open-cut coal roadway," Coal Engineering, no. 3, 2010.

[5] H. Wang, Y. Chen, and D. Zhang, "Combined support and effect analysis of large section open-open cut," China Coal, no. 9, 2010.

[6] S. Xie, F. He, and S. Zhang, "Combined support technology of open-cut truss and anchor cable for large-section composite mudstone roof," China Mining, vol. 17, no. 9, 2008.

[7] L. Xing, Research on Bolt (cable) Support Technology for LargeSpan Open-Cut Roadway, Xi'an University of Science and Technology, Xi'an, China, 2008.

[8] Y. Wang, F. Wei, and J. Bai, "Large-section open-cut support technology for fully mechanized mining face under the goaf," Coal Science and Technology, vol. 39, no. 6, 2011.

[9] J. Wang, S. Yang, W. Wei, J. Zhang, and Z. Song, "Drawing mechanisms for top coal in longwall top coal caving (LTCC): a review of two decades of literature," International Journal of Coal Science Technology, 2021.

[10] D. Z. Kong, S. J. Pu, Z. H. Cheng, G. Y. Wu, and Y. Liu, "Coordinated deformation mechanism of the top coal and filling body of gob-side entry retaining in a fully mechanized caving face," International Journal of Geomechanics, vol. 21, no. 4, Article ID 04021030, 2021.

[11] J. F. Lou, F. Q. Gao, J. H. Yang et al., "Characteristics of evolution of mining-induced stress field in the longwall panel: insights from physical modeling," International Journal of Coal Science Technology, 2021.

[12] Z. Jiang, K. Lei, and D. Liu, "Bolt and cable support technology for thick-top coal and large-span open-off cut," Coal Mine Safety, vol. 43, no. 2, 2012.

[13] H. Liu, Mechanics of Materials, Higher Education Press, Beijing, China, 4th edition, 2003. 